\title{
Anarquistas y racionalistas en el marco de la "Liga Popular para la Educación Racional de la Infancia". Montevideo, 1911-1916
}

\section{Anarchists and rationalists in the "Liga Popular para la Educación Racional de la Infancia". Montevideo, 1911-1916}

\author{
Gerardo Garay Montaner \\ Universidad de la República Oriental del Uruguay \\ (Uruguay) \\ gerardo.garay@gmail.com
}

\section{Resumen}

El presente artículo busca abordar, desde una perspectiva histórica, parte del contexto intelectual que enmarcó las discusiones en torno a la experiencia educativa con participación del movimiento anarquista más importante en el Uruguay: la "Liga Popular para la Educación Racional de la Infancia". El caso es de singular importancia porque muestra las tensiones entre sectores del movimiento anarquista y sus posicionamientos ante la creciente influencia del Estado en la educación de los sectores obreros.

Palabras Clave: Educación racionalista - Educación libertaria - Pedagogía anarquista - Educación en el Uruguay 


\begin{abstract}
This article seeks to approach, from a historical perspective, the intellectual context that framed the discussions concerning the most important educational experience with anarchist participation in Uruguay: "Liga Popular para la Educación Racional de la Infancia". The case is extremely relevant since it shows the tensions between different sectors of the anarchist movement and their positions facing the increasing influence of the State in the education of the working class.
\end{abstract}

Key Words: Racionalist education - Education for freedom - Anarchistic pedagogy

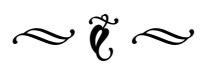

\section{Introducción}

El presente artículo propone abordar el contexto intelectual de las discusiones en torno a la experiencia educativa racionalista más importante en el Uruguay: la "Liga Popular para la Educación Racional de la Infancia" (en adelante, LRM), entre 1911 y 1916. El "racionalismo pedagógico", en el sentido que contribuyera a propagar Francisco Ferrer i Guardia (1859-1909) en Cataluña, si bien estuvo presente en el Río de la Plata desde inicios del siglo $\mathrm{XX}$, adquirió una vitalidad renovada con ocasión del proceso, ejecución y muerte de Ferrer en 1909. La hipótesis de éste trabajo sostiene que en la experiencia de la LRM, se hicieron cada vez más evidentes las tensiones y contradicciones entre un sector "racionalista puro" y otras figuras que identificaron "racionalismo" y "anarquismo" de un modo lineal. La discusión tomó estado público en los principales medios de difusión libertarios y racionalistas, pero el debate no siempre estuvo organizado en torno a diferencias tácticas. Consideramos importante prestar atención a elementos subjetivos que condicionaron el apoyo del anarquismo al proyecto racionalista.
La LRM buscó incidir en la agenda educativa de la instrucción pública uruguaya. Para ello se sirvió de una revista; Infancia, su órgano oficial de prensa desde 1912 hasta 1916. En este artículo se tendrán en cuenta otras publicaciones de la época, especialmente la revista Educación Sociológica (1911-1912), que fue, en parte, su precedente. ${ }^{1}$ Hasta el momento no hay ningún trabajo que haya estudiado esta experiencia, a excepción de un artículo exploratorio del historiador catalán Pére Solá I Gussinyer. ${ }^{2}$

1. La revista "Infancia", salió con regularidad, siendo, a través de los cuarenta ejemplares de carácter mensual (lo que constituye un corpus de 600 páginas aproximadamente), una revista única en su ámbito. Esta publicación representa un testimonio muy relevante del proceso de constitución de la LRM, sus opciones teóricas y las noticias de sus dificultades ideológicas y materiales para la empresa propuesta. El cuerpo total se ha logrado reunir, complementando los números hallados en la Biblioteca Nacional de la República Oriental del Uruguay con los de la biblioteca del International Institute of Social History de Amsterdam, obtenidos gracias a la gentileza de la investigadora española María Miguelañez. La revista Educación Sociológica fue dirigida por Otto Niemann, contó con siete números, desde octubre de 1911 a abril de 1912.

2. SOLÁ Y GUSSINYER, Père, "Los grupos del magisterio racionalista en Argentina y Uruguay hacia 1910 y sus actitudes ante la enseñanza laica oficial”, en 
El estudio del lenguaje utilizado por los autores de la LRM, contribuye a complejizar ciertas opiniones usuales de la historiografía corriente. Por ejemplo, aquellas que señalan que la "educación racionalista" fue "un tipo específico de educación libertaria", ${ }^{3}$ o parte de la estrategia del movimiento anarquista. Asimismo cuestiona que los planteamientos ideológicos en el Uruguay de este periodo, en términos generales, "reprodujeron", sin más, "la evolución del pensamiento social europeo". ${ }^{4}$ Es decir, coopera, por un lado, a comprender la experiencia de la LRM en su especificidad, avanzando en las complejidades de adaptación de las ideas racionalistas en Montevideo a inicios del siglo XX. Por otro lado, nos permite abordar la trama de opiniones que sobre educación tuvo el movimiento anarquista en este periodo y el discurso educativo-pedagógico que produjo.

\section{La educación de la infancia en el Uruguay a inicios del siglo XX}

El establecimiento de un sistema escolar "moderno" en el Uruguay marchó de la mano del creciente peso que fue adquiriendo la ideología liberal hacia fines del siglo XIX. ${ }^{5}$

Historia de la Educación, Salamanca, 2010, V. 1, pp. 55143.

3. HERRERA, Diego, Las escuelas libertarias en el contexto de estructuración y consolidación del sistema educativo argentino (1898-1915), Tesis de Licenciatura, Universidad de Buenos Aires, 2009. Disponible en: <http:// comunicacion.fsoc.uba.ar/tesinas_publicadas/2141.pdf>.

4. D’ ELIA, Germán; MIRALDI, Armando, Historia del movimiento obrero en el Uruguay. Desde sus orígenes hasta 1930, Ediciones de la Banda Oriental, Montevideo, 1984, p. 84.

5. ARDAO, Arturo, Racionalismo y liberalismo en el
Al mismo tiempo que se daba este paulatino aumento de protagonismo, la influencia ideológica de la Iglesia Católica en los sectores económicamente dominantes fue decayendo. En palabras de José Barrán, la "represión del alma" a fines del siglo XIX y comienzos del siglo $\mathrm{XX}$ se produjo "fuera del hogar" y ya no exclusivamente en el confesionario católico: "la escuela vareliana" y el "consultorio del médico", fueron sus otros lugares privilegiados. ${ }^{6}$

E1 Estado uruguayo se abocó fundamentalmente en las últimas décadas del siglo XIX $\mathrm{y}$ en las primeras del XX, a dos tareas visualizadas como urgentes: la necesidad de la 'nacionalización' de los numerosos contingentes de inmigrantes proveniente del viejo mundo y el proceso de disciplinamiento e inclusión de la población rural criolla en una estructura estatal moderna. ${ }^{7}$ Para ello, fue necesario construir un modelo de integración y pertenencia; es decir, llevar adelante políticas de formación de ciudadanía, entre las cuales, la educación primaria se constituyó en pieza fundamental.

La reforma de la educación primaria a nivel nacional impulsada por José Pedro Varela (1845-1879) a partir de 1876, sentó las bases de la escolarización moderna en el Uruguay. Antes de ella, la enseñanza no había sido una preocupación nacional, ni de las clases cultas,

Uruguay, Universidad de la República, Montevideo, 1962.

6. BARRÁN, José, NAHUM, Benjamin, Historia Rural del Uruguay Moderno (1851-1885), Banda Oriental, Montevideo, 1967, p. 283.

7. ISLAS, Ariadna, La Liga Patriótica de Enseñanza. Una historia sobre ciudadanía, orden social y educación en el Uruguay (1888-1898), Banda Oriental, Montevideo, 2009, pp. 18-19. 
ni de las dominantes. ${ }^{8}$ El sistema escolar resultante contó con el decidido control del Estado, con una compleja administración creada para ese fin y con un "nuevo grupo social”, según expresión de Carlos Rama, que se estructuró a partir de los conocimientos técnicos y del ropaje "misional" que las políticas gubernamentales le fueron invistiendo: el de los docentes. ${ }^{9}$

Después de un periodo de estancamiento, el impulso "batllista" ${ }^{10}$ que buscó popularizar la enseñanza significó -especialmente a partir de la presidencia de Claudio Williman (18611934) en 1907 y de la segunda presidencia de José Batlle y Ordóñez en 1911- un avance significativo, rompiendo en buena parte, las vallas económicas que impedían el acceso a la cultura de vastos sectores y alimentando la expectativa de ascenso social cada vez más arraigada en el imaginario colectivo. Como fenómeno bifronte, en el contexto de un país dependiente, la educación cumplió el papel de satisfacer las necesidades del desarrollo capitalista industrial y la exigencia de contar con un número significativo de técnicos, profesionales y obreros especializados. Al mismo tiempo, garantizaba una población con un mínimo de cultura, indispensable para consolidar los "hábitos democráticos". El conjunto de estas medidas apuntaron a "crear una cultura de la masa", en la que la

8. CASTRO, Julio, El banco fijo y la mesa colectiva: Vieja y Nueva Educación, MEC, Montevideo, 2007, p. 55.

9. RAMA, Carlos, José Pedro Varela, sociólogo, Editorial Medina, Montevideo, 1957, p. 43.

10. Se denomina "batllismo", a la corriente política iniciada a finales del siglo XIX en Uruguay por José Batlle y Ordóñez (1856-1929), quien realizó una profunda reforma del Estado como presidente del país en las dos primeras décadas del siglo XX. educación y el voto fueron "los axiomas de la acción, de la reforma de la sociedad". ${ }^{11}$

La política social del batllismo representó en el Uruguay la implementación de los postulados social-demócratas, en el sentido de que tendió a imponer el programa mínimo del socialismo dentro de las formas institucionales de la democracia burguesa. Tal vez, debido a esto, las demás expresiones de partidos y movimientos de la izquierda revolucionaria tuvieron un escaso o enlentecido crecimiento en este periodo. En algunos miembros de los movimientos anarquistas, entre los años 1911 y 1913, prevaleció cierta tendencia a valorar los logros sociales y laborales del batllismo como conquistas tácticas del movimiento obrero. Estos grupos se inspiraban en una tradición reciente $\mathrm{y}$, si bien constituían una expresión minoritaria en el contexto general de las corrientes anarquistas, mantuvo una presencia constante.

Efectivamente, la última década del siglo XIX dejó como saldo un sector "educacionista" consolidado al interior del movimiento obrero internacional. $\mathrm{Su}$ convencimiento estuvo pautado por la idea de que la enseñanza era un medio potente para combatir la ignorancia $y$ una palanca fundamental para mover las estructuras sociales. El $1^{\circ}$ de mayo de 1908 este sector lograría afianzar su impulso con la conformación en París de la "Liga Internacional para la Educación Racional de la Infancia”. Sus bases constitutivas establecieron, en primer lugar, la necesidad de que la educación de los niños se fundara sobre una base científica y racional, lo cual implicaba el rechazo de toda

11. HIERRO, Luis Antonio, Batlle. Democracia y reforma del Estado, Ediciones de la Banda Oriental, Montevideo, 1977, p. 66. 
noción mística o sobrenatural. En segundo orden, dispusieron que la instrucción era una parte de la educación y que ésta debía comprender también, junto con la formación de la inteligencia, "el desarrollo del carácter, la cultura de la voluntad, la preparación de un ser moral y físico bien equilibrado, cuyas facultades estén armónicamente asociadas y elevadas a su máximo de potencia”. En tercer lugar, exhortaron a que la educación moral fuera eminentemente práctica, que resultara del ejemplo y que se apoyara "sobre la gran ley natural de solidaridad”. Por último, consideraron importante que los programas y los métodos estuvieran adaptados a la psicología del niño. ${ }^{12}$

En este contexto, surgió en 1911, en Montevideo, la LRM. Su cometido, según puede leerse en el primer punto de su base programática, estaba orientado a "hacer ambiente", propagando la necesidad de la educación racional y además, a "facilitar, en centros creados ex profeso, una preparación para la vida". ${ }^{13}$ En estos nuevos centros de enseñanza se impartiría una educación libre de prejuicios y dogmas, tanto religiosos como políticos. El anarquismo también estaba incluido en esta proscripción, a pesar de que varios de sus animadores principales pertenecían a esa corriente.

Tanto Educación Sociológica como Infancia fueron enviadas a las autoridades de la Dirección General de Instrucción Primaria (DGIP), según consta en "publicaciones recibidas" de los Anales, órgano oficial de

12. En revista Francisco Ferrer, Buenos Aires, 15/9/1911, No 9, p.12.

13. La Comisión, "Liga Popular para la Educación Racional de la Infancia. Bases”, en Educación Sociológica, Montevideo, 11/1911, № 2, p. 12. esta institución. ${ }^{14} \mathrm{~A}$ pesar de ello, no hay ninguna mención a la fundación de la LRM, ni a la Escuela Integral (único colegio patrocinado por la LRM) como tampoco se alude a la discusión de temas vinculados al "racionalismo". No sabemos si este silencio fue deliberado. Nuestra hipótesis sostiene que las autoridades gubernativas en materia de educación desconocían o comprendían de un modo muy superficial las inquietudes y advertencias de los grupos racionalistas. Esta situación era muy similar a la que se daba respecto de los postulados anarquistas.

Sobre éstos últimos, es ilustrativo el caso del filósofo Carlos Vaz Ferreira, figura destacada, entre otras cosas, por su participación como vocal de la Dirección General de Instrucción Primaria desde el año 1900 a 1915. Con posterioridad al cumplimiento de esta tarea y ejerciendo ya el rol de catedrático en régimen libre por la Universidad de la República, realizó en 1920, una serie de conferencias denominadas "Sobre los problemas sociales”. En ellas, Vaz Ferreira se propuso afrontar de un modo "directo" estos asuntos, abordándolos libremente, sin atarse a "esquemas paralizantes". Este modo de pensar y de sentir lo condensó en una "fórmula", una "solución", dotada de suficiente plasticidad como para poder contemplar las diferencias. Sus rasgos constitutivos eran: la preservación del individuo ("no se puede abandonar al individuo antes de cierto momento") y la preservación de la libertad ("es necesario abandonarlo a la libertad una vez que se ha llegado hasta cierto grado"). ${ }^{15}$ Ahora bien,

14. Anales de Instrucción Primaria, DGI, Montevideo, Año XI, T. XI, No 1-15, 4/1912- 6/1913, pp. 639.

15. VAZ FERREIRA, Carlos, Sobre los problemas sociales, Homenaje de la Cámara de Representantes de la República 
en la dicotomía (liberalismo-socialismo) que Vaz Ferreira señaló como primera tensión que debía ser resuelta por infecunda ("polaridad no polarizante", según sus palabras), el autor sostuvo que "la oposición de esas dos tendencias es, en verdad, lo fundamental: el análisis de otras nociones, propiamente no agregaría nada esencialmente a ellas". Por ejemplo, al analizar la idea de "anarquismo", ${ }^{16}$ argumentaba que uno de los sentidos que propone, -el literal, "no gobierno"-, "no sería sino el "individualismo extremo":

supresión de toda ley, de toda coerción, individualismo absoluto. (En este sentido tiene a su favor un mérito muy simple: ser... el ideal; pero ideal que postula un demasiado profundo cambio en la naturaleza humana, sin el cual sería mal extremo)... lo esencial sigue siendo el conflicto de las ideas de igualdad y de libertad. ${ }^{17}$

Es decir que, en la propuesta de una de las figuras intelectuales más influyente en las primeras décadas del siglo $\mathrm{XX}$ uruguayo, el anarquismo como teoría social y política, no tenía nada para aportar a las grandes cuestiones sociales y políticas de la humanidad.

Otro ejemplo en el que Vaz Ferreira mostró una discutible comprensión de las ideas anarquistas, fue el que aludía a la división tajante que a menudo se establece entre trabajo intelectual y trabajo manual. En opinión de Vaz, los "revolucionarios" tienen que entender que el trabajo intelectual debe ser defendido también por ellos, de otro modo, toda revolución está condenada al fracaso. Consideraba que generalmente,

Oriental del Uruguay, Montevideo, 1963, p. 74.

16, Ídem, p. 24 (subrayado nuestro).

17, Ídem, p. 25.

26 burgueses y revolucionarios habían actuado igual, siguiendo los mismos parámetros en la acción: habían atacado "lo bueno y lo malo, ciegamente". ${ }^{18}$ Así, la incomprensión de que el trabajo intelectual es también trabajo, estaba incluso, en "espíritus superiores". Un ejemplo "impresionante" de esto -afirmaba Vaz- es el cuento popular de Tolstoi "Historia de Iván el imbécil", en el que se muestran crudamente las relaciones entre el trabajo espiritual y el trabajo material. Su "error capital", el de Tolstoi, "es el de excluir el trabajo intelectual como trabajo, la condenación del trabajo espiritual". Y la "fórmula" es: "quien no tiene callos en las manos, no tiene derecho a comer; no quien no trabaja, sino quien no tiene callos en las manos. Y la idea de que además de poder trabajar con las manos, se puede trabajar con la cabeza, es idea del diablo". ${ }^{19}$ Esta interpretación que Vaz Ferreira hizo del cuento era parcial ya que al final del mismo, lo que la esposa de Iván dice al diablo es: "Pero existe en este reino una costumbre, una sola: al que tiene callos en las manos se le dice: “Ponte a la mesa!", y al que no los tiene: “ $¡$ Come las sobras!”. ${ }^{20}$ Es decir -y esto se vislumbra en más de un momento en el cuento- que no se deja a nadie morir de hambre en el reino de Iván; ni siquiera al diablo, que poseyendo todo el oro del mundo, se niega a trabajar con sus manos para satisfacer sus necesidades y espera, con su dinero, hacer que los demás le sirvan. Lo que está en juego aquí, no es el desprecio del trabajo intelectual sino el rechazo a la actitud "aristocrática" de pretender normalizar las diferencias sociales y económicas basadas en

18. Ídem, p. 68.

19. Íbidem.

20.TOLSTOI, León, Obras Completas, Aguilar, Madrid, 1981,T.II, p. 1466. 
la disparidad de instrucción, pretendiendo conservar un mundo de pseudovalores en el que se justifique la explotación del otro. La fórmula que subyace en Tolstoi es más bien el viejo principio anarquista de libertad e igualdad: trabajar con las manos tanto como con la inteligencia.

De este modo, parecería que el conocimiento de las ideas anarquistas por parte de una de las figuras más lúcidas de los grupos dirigentes de Montevideo a inicios del siglo $\mathrm{XX}$, no fue motivo de un estudio detallado, no hubo necesidad de rebatir postulados que no se percibían como una amenaza a la marcha avasallante de la instrucción estatal.

\section{¿Racionalismo o anarquismo?}

En el transcurso de la experiencia de la LRM fueron en aumento las tensiones entre un sector "racionalista puro" y otras figuras que identificaron la prédica racionalista con los ideales del anarquismo. La discusión, que tomó estado público, no siempre evidenció diferencias tácticas. En realidad, fueron componentes de otro orden los que llevaron a instalar la acusación por parte del movimiento anarquista local, de que la acción de la LRM carecía del carácter racional que profesaba y que la presencia de anarquistas en su constitución y desarrollo era una claudicación de principios.

El movimiento racionalista en la Argentina sirvió de espejo al que se iniciaba en el Uruguay; imagen conflictiva, sin embargo, en el que el rótulo de "racionalista" fue motivo de disputa. La preocupación sobre el alcance de una educación racionalista se venía dando desde hacía tiempo en la vecina orilla, especialmente desde las páginas de la revista Francisco Ferrer. En el primer número, su director Samuel Torner ${ }^{21}$ estableció claramente el propósito de la publicación y del movimiento racionalista en su conjunto. Hasta el momento, a su juicio, la enseñanza racionalista patrocinada por los sectores populares, "carecía de ambiente", reduciéndose a unos pocos, malgastando energías, sostenían una Escuela Moderna a fuerza de grandes sacrificios, con escasos medios y quizá, con "falsa orientación pedagógica". De este modo, afirmaba Torner, "no podía cumplir con su alta tarea y competir con las del Estado". El objetivo para ese momento resultaba claro, había que "levantar entre todos la Escuela Moderna, la obra de Francisco Ferrer, sin odios, sin política, sin religión, sin sectarismo alguno". ${ }^{22} \mathrm{El}$ pedagogo brasilero Mauricio de Medeiros fue convocado desde las páginas de la revista argentina para señalar que el racionalismo era un método de enseñanza, vale decir, "el conjunto de medios los más cortos y más seguros para llegar a la verdad". Por tanto, la ausencia de compromiso ideológico debe ser condición excluyente: "ser pues racionalista no implica de ninguna manera ser anarquista o antipatriota". ${ }^{23} \mathrm{La}$

21. Reconocido activista español, en 1907 con Antonio Manuat creó en Valencia la Sociedad primitiva de instrucción laica y la Escuela Moderna, fue director de ésta última, de inspiración ferreriana y director también de su órgano de prensa, Humanidad Nueva en el periodo 19071909. Colaborador de las revistas Enseñanza Moderna de Irún, Nueva Vida de Mataró, La Tramontana, entre otras, IÑIGUEZ, Miguel, Esbozo de una Enciclopedia histórica del anarquismo español, Fundación Anselmo Lorenzo, Madrid, 2001, p. 585.

22. TORNER, Samuel, "Editorial”, en Francisco Ferrer, Buenos Aires, 1/5/1911, No 1, p. 2.

23. DE MEDEIROS, Mauricio, "Enseñanza racionalista”, en Francisco Ferrer, Buenos Aires, 
disyunción final mostraba una concepción polémica del anarquismo.

El tema se retomaría tiempo después, para referirse a la "educación neutral", epocalmente coincidente con el primer número de "Infancia". La tesis del articulista era tajante: la educación debía ser "racional", esto es, ni "anarquista" ni "neutral", la diferenciación entre ellas no estaba exenta de valoraciones:

La enseñanza neutral solo pueden propagarla los defensores del 'stato quo', los positivistas oportunistas y aunque esto por si sólo ya es mucho para condenarla, no basta para alejarla de la pretendida eficacia intelectual y moral tanto individual como colectiva; lo neutro es lo indefinido, es lo indeterminado, es siempre un elemento pasivo, nunca es activo. Lo pasivo no acciona, no produce nada, a lo más es lastre, sirve de rémora. Ser neutral es ser inferior moralmente". ${ }^{24}$

En el otro extremo, siempre en opinión del articulista, la "enseñanza anarquista" tampoco podía ser una opción, ya que no se distinguiría de las demás enseñanzas dogmáticas. Si partimos de la base de que no hay libertad sin deliberación, los niños que frecuentaban una escuela anarquista sólo podían tener una concepción distorsionada de la libertad al percibir al ideal anarquista como la imposición de un único camino, sin un debate previo.

La enseñanza racionalista entonces era "superior" a las demás porque no era pasiva ni dogmática, "su amiga predilecta" era la ciencia, ya que exponía los hechos

15/5/1911, No 2, pp. 11-12.

24. AMADOR, “Neutral, Anarquista y racional”, en Francisco Ferrer, Buenos Aires, 1/1912, No 16, p. 3. comprobados y comprobables y todas las opiniones emitidas sobre el punto en cuestión y eran los estudiantes quienes aceptaban la que estaba más en concordancia con los conocimientos científicos adquiridos. La enseñanza racionalista "no tiene otro afán que buscar la verdad para presentarla tal cual es y para lo cual investiga, compara y deduce". ${ }^{25}$

Esta jerarquización realizada por Amador, tenía la característica de que era planteada desde la opción personal ideológica del anarquismo. Esto significaba que, la postura racionalista, como método pedagógico era, para el autor, la consecuencia natural de los postulados del anarquismo y exigencia inexcusable de defensa de la libertad de los niños. La ciencia, una vez más, aparecía por fuera de las disputas ideológicas, en el derrotero de la "Verdad" inexpugnable.

Entre racionalismo y anarquismo, no obstante, las cosas estaban más entreveradas de lo que se suponía. Existía en la mayoría de los escritores de esta publicación educacional una indudable deuda teórica y afectiva con el anarquismo que se expresó, entre otras cosas, en ciertas preferencias editoriales. En la edición No 16 , por ejemplo, se realizó un importante homenaje a J. P. Proudhon y su rostro aparece en tapa. ${ }^{26}$ Entre muchos activistas del movimiento ácrata rondarían preguntas tales como: ¿son lo mismo racionalismo y anarquismo? ¿E1 racionalismo es una consecuencia "natural" del anarquismo o es un modo particular de éste? ¿Coinciden al menos en su propósito?

25. Ibídem.

26. En revista Francisco Ferrer, Buenos Aires, 1/1912, No 16. 
La necesidad de responder estos interrogantes continuaron en los números subsiguientes. Una vez más, Torner buscaba aclarar que la "escuela racional" no era anarquista y su enseñanza no era sinónima de doctrina anarquista: "haced de los niños hombres y no discípulos. La humanidad necesita hombres $y$ el estudio racionalista desprogramizado debe y puede crearlos... de lo contrario, esa educación se convertirá en un nuevo evangelio y los momentos éstos son de desvangelización total". ${ }^{27} \mathrm{La}$ educación racionalista se proponía salvaguardar íntegramente la personalidad del niño, contribuir a formar un espíritu que aceptara todo progreso. Torner se preguntaba, “¿será un anarquista?”. Su respuesta señalaba que era imposible saberlo. Lo que sí podía asegurar era que sería "un hombre que, con criterio propio, discernirá”. Para esto, la escuela racionalista no podía ser anarquista, "pues teniendo como base la investigación y comprobación científica resulta que no puede tener, como no lo tiene la ciencia, un programa cerrado". ${ }^{28}$

Dos meses más tarde surgió, también en las páginas de la revista Francisco Ferrer, la primera discrepancia. En opinión de Miguel Expósito, enseñanza racionalista y enseñanza anarquista eran sinónimas: "si el racionalismo es la síntesis de la ciencia positiva, y la anarquía, concibiéndola en su más elevada concepción filosófica, se forja con el positivismo de toda la ciencia racionalista, no veo línea divisoria entre ambas". La discrepancia no era una cuestión de términos solamente, en opinión del articulista, el error fundamental de Torner estaba en entender que el anarquismo tenía un programa cerrado: "Forjada en el yunque

27. En CHANTEMUR, “Racionalismo”..., Op. Cit., p. 3. 28. TORNER, Samuel, “Editorial”, Op. Cit., p. 3. filosófico de la ciencia racional positiva, su existencia vital se desenvuelve paralelamente a ésta, y por consecuencia sería absurdo el pretender señalar límites de estancamiento en ella". ${ }^{29}$

La discusión sin embargo no prosperó. Así, el mismo número de la revista en el que Expósito señalaba sus discrepancias, fue el escenario a su vez de la rápida respuesta del director, que constituyó la última intervención sobre este tema en las páginas de Francisco Ferrer. El argumento era reiterado: pretender que nuestros hijos siguieran nuestras ideas y defendieran nuestros principios era una actitud esperable en una mentalidad proselitista, ya fuera católica, protestante o atea en materia religiosa; de un republicano o un socialista en política. Sin embargo, ser anarquista era defender un ideal más elevado, implicaba sostener un concepto más amplio de libertad que llevaba a respetar las ideas ajenas, muy especialmente la de los niños "que no pueden aun discernir nuestros ideales, aunque éstos sean, como los anarquistas, los más bellos que haya concebido cerebro humano". Al parecer, las principales resistencias provenían de sectores preocupados en la preparación para una revolución social -que se percibía como inminente- que en la búsqueda de una mejor educación:

¡Cuántos hay que dicen que ya somos bastante instruidos y lo que precisamos es la lucha abierta para conquistar nuestro derecho a la vida! Pero lo dicen por ellos creyendo que los demás están en las mismas condiciones de predisposición a la transformación. No, hay que ser más prácticos, y sobre todo, tener más

29. EXPÓSITO, Miguel, "Enseñanza racionalista", en Francisco Ferrer, Buenos Aires, 12/1911, № 12, p. 6. 
fe en la libertad, en la virtualidad de la escuela racional que nos proporcionará sin que tenga que apellidarse anarquista, los hombres conscientes, creadores de la Humanidad Nueva. ${ }^{30}$

Conviene señalar, como corolario a este breve intercambio realizado en la revista Francisco Ferrer, que los autores racionalistas se reconocían explícitamente como defensores de los postulados anarquistas. E1 reproche a sus pares radicaba, por una parte, en una escasa practicidad, producto de cierta "impaciencia" revolucionaria y por otro, de no extremar las convicciones ácratas, retaceando la confianza en la libertad individual como motor de transformación.

Por su parte, en línea de continuidad con estas afirmaciones, pero sin reconocer ni remitir a las páginas de la revista argentina, la LRM continuó la discusión sobre los vínculos entre educación racionalista y educación anarquista. El tono que alcanzó el intercambio de opiniones mostraría que las diferencias entre los grupos en disputa no eran exclusivamente de orden táctico.

Desde el primer número de la revista Infancia La LRM dejó plateada su posición:

Del mismo modo que consideramos perniciosa y sistemática la enseñanza que el estado proporciona, y no puede ser de otro modo si no quiere negarse a sí mismo; como lo es la que se da a base religiosa... consideramos perniciosa y funesta la que se suministrara a base del ideal filosófico conocido por anarquismo, pues todo lo que tienda a formar ideas hechas en los niños es repudiable, doble más cuando,

30. TORNER, Samuel, "Contestando", en Francisco Ferrer, Buenos Aires, 11/1911, No 12, p. 7. como pasa con el anarquismo, no es comprendido por muchísimas personas mayores de reconocida ilustración y si retajado vergonzosamente por otros que se dicen poseídos de su alcance... ¡Cuánto más difícil y escabroso resultaría, pues para el infante!. ${ }^{31}$

Más allá de la debilidad de la segunda parte del argumento, que no permitía aclarar cómo la dificultad en la comprensión de los postulados anarquistas por parte de algunos adultos, era impedimento para su enseñanza a los niños, es interesante notar que, los motivos por el cual había que abstenerse a la posibilidad de una "educación libertaria", eran los mismos que llevaban a aceptar la educación estatal y religiosa. Por otra parte, aparecía una variante con respecto a la discusión que se diera en la revista Francisco Ferrer: el reproche que se realizaba a la interna de los grupos ácratas de que muchos de sus defensores no vivían de acuerdo a las ideas que profesaban. No obstante, del mismo modo que en la publicación de la vecina orilla, la tradición que se convocaba en los números sucesivos para fundamentar la postura de no enseñar "ideas hechas", o la advertencia sobre el perjuicio de la enseñanza estatal, eran preponderantemente de extracción anarquista: escritos de Ricardo Mella, Sebastián Faure, Jean Grave, Paul Robin, editoriales de Acción Libertaria. Una veintena de artículos a lo largo de cinco años mostraron que la discusión distó mucho de quedar saldada.

El debate trascendió la prensa anarquista. En tal sentido, Albano Rosell ${ }^{12}$ publicó en el

31. NIEMANN, Otto, "Deslinde de términos", en Infancia, Montevideo, 3/1912, № 3, pp. 22-23.

32. Albano Rosell (1880-1964), De origen proletario, 
diario La Reforma de Montevideo el artículo "Educación Racionalista. Comentarios", y pocos días después le dió difusión desde las páginas de Infancia. Hacer pública en la "prensa burguesa", una discusión originada en la "interna" del movimiento obrero era decisión reprochable. Rosell se excusó alegando la "necesidad" de "poner en claro una situación insostenible referente al racionalismo uruguayo". ${ }^{33}$ A su juicio, lo peculiar de nuestro caso consistía en que mientras "en todas partes de la Tierra los enemigos de la educación libertadora, de la educación verdadera, científica, racionalista, son los elementos retardatarios, los amarrados a la tradición, al pasado... en el Uruguay los términos se han invertido, es decir, los enemigos de la educación razonada, verdaderamente popular y científica, son los que se dicen más avanzados: los anarquistas". ${ }^{34}$ Esta acusación no pasaría desapercibida, tanto por la generalización que implicaba (aunque tuvo ocasión de reducirla posteriormente a "unos pocos") como por la gravedad de su alcance, especialmente a escasos cuatro años de los sucesos de Montjuic. ${ }^{35}$

fue obrero tejedor y autodidacta, realizó una intensa labor como pedagogo y una amplísima obra literaria, que abarca géneros tan dispares como el teatro, la poesía, el ensayo y la literatura infantil. Fue amigo de Ferrer i Guardia y de Mateo Morral, en este sentido, fue fiel a la idea de instauración de "Ligas" de educación racionalista de la infancia en todo el mundo. Sostuvo tesis integralistas en la línea de Robin. A lo largo de su vasta producción, utilizó los siguientes seudónimos: "Antonio Roca”, "Dr. Frank Aube”, "Laureano D’Ore", "Germina Alba", "J. E. Martî", "Nano de Sabadell", "Victoria Zeda”. En IÑIGUEZ, Miguel, Diccionario..., Op. Cit., p. 530.

33. D’ORE, Laureano, "Educación Racionalista. Comentarios”, en Infancia, Montevideo, 6/1913, № 18, p. 57.

34. Ibídem.

35. Es decir, el proceso de encarcelamiento, juicio y
El momento era peculiar además porque la deseada Escuela integral, "práctica viviente del racionalismo educativo" estaba a punto de concretarse. Su director, Albano Rosell, recibía fuertes críticas de sectores anarquistas quienes pusieron en duda el carácter "racionalista" del emprendimiento, y censuraron las muestras de apoyo de otros colectivos, como el "Centro Carlos Marx". Las intervenciones de Albano Rosell no estuvieron orientadas a tender puentes, convencido de que las objeciones planteadas tenían su origen en simples mezquindades ${ }^{36}$.

Una vez más se aclaraba la perspectiva que movía la fundación de la escuela y toda la obra de la LRM:

La Escuela Integral, y lo digo bien alto y bien claro para que no de lugar a dudas, no es anarquista, no pretende serlo, $y$ antes que ser así primero cerraría sus puertas; y si el racionalismo, para serlo, tiene que enseñar anarquismo, la Escuela Integral no es ni siquiera racionalista". ${ }^{37}$

fusilamiento del pedagogo catalán Francisco Ferreri i Guardia el 13 de octubre de 1909, fundador y director de la Escuela Moderna de Barcelona, referente mundial del racionalismo pedagógico.

36. “... el anarquismo uruguayo, quizás diría mejor, el sudamericano, se distingue por una podredumbre, inconsecuencia y fanatismo tan exótico, que se puede bien afirmar que es un caso único en esta clase de movimiento social y filosófico. En una porción de actos en que han tomado parte activa los llamados mejores anarquistas uruguayos, han evidenciado bien tristemente la pobre y tonta concepción de estas ideas que enaltecieran tantos pensadores mundiales, y ellos, precisamente dicen que nuestra escuela no es racionalista porque no hace obra anarquista”. En D' ORE, Laureano, “Educación Racionalista...", Op. Cit., p. 58.

37. Ibídem. 
A pesar de la incansable difusión de estas convicciones, Rosell afirmaba que los representantes locales del anarquismo nunca debatieron por escrito, ni de forma oral, sino que la falta de apoyo había sido "solapada", "rastrera". 38

Es interesante preguntarse si en verdad eran tan pocos aquellas figuras que desde el movimiento anarquista ponían obstáculo al proyecto de la LRM; la preocupación constante, la vivacidad de los escritos y la cantidad de los mismos, hacen pensar más bien lo contrario. Desde las páginas de $E l$ Anarquista, se reprochaba el hecho de que la discusión tomara estado público; la respuesta, contra su pesar, estaba dada por la "obligación" que este acontecimiento exigía: "pretende, sin conseguirlo, herir nuestra epidermis, poniéndonos en el lugar de los reaccionarios europeos, porque no nos hemos adherido a su obra de educación neutral". ${ }^{39}$

Para este grupo congregado en torno a $E l$ Anarquista, la tarea de la LRM y la Escuela Integral se inscribía en una concepción pedagógica "neutral" y por tanto, contraria a los intereses libertarios:

en esa Liga forman connubio individuos de todas las ideas en el orden religioso, político y filosófico y esa Liga ha fundado una Escuela que se llama Integral en donde se da a la niñez una educación anti-sectaria

38. "Interinamente, los buenos, los sinceros, los desapasionados y razonadores sabrán a qué atenerse referente a esta obra que unos ilusos, fanáticos, viciosos y castrados de intelecto, pretenden mancillar. El desprecio debe ser el premio, mientras seguimos el camino más fuertes, más seguros, más íntegros, fuera del contacto maleante de fanatismos", Ídem, p. 59.

39.“ ¿Racionalismo o anarquismo?”, en El Anarquista, Montevideo, 15/6/1913, No 5. y anti-dogmática en lo religioso, en lo político y en lo social y por consecuencia anti-anarquista, ya que según su director 'la Anarquía es una secta' y 'sería tan criminal hacer de los niños católicos como anarquistas'. ${ }^{40}$

Se reivindicaba al movimiento anarquista como el primero en crear escuelas "modernas" en el Uruguay en 1906 "y si entonces, no se fundó una Liga como la que ahora funciona, fue porque nosotros no estábamos dispuestos a claudicar de nuestros principios sociológicos y científicos y entendíamos como entendemos ahora, que la educación racionalista ha de ser anarquista si no se quiere hacer eunucos. Y por eso mismo no colaboramos ni en la Liga, ni en la Escuela Integral". ${ }^{41}$

La convicción pedagógica de este grupo puede sintetizarse en los siguientes puntos: la educación de la niñez ha de basarse en primer lugar en la naturaleza; sólo es posible enseñarle aquellas verdades que han sido demostradas científicamente; entre ellas, "el porqué de la riqueza, el porqué del Estado, el porqué de la religión, la moral, etc.”. ${ }^{42}$ En la misma línea de pensamiento de Ferrer i Guardia, se entendía que los grandes temas sociales y políticos, las desigualdades sociales, la lucha de clases, etc. eran evidencias empíricas proporcionadas por el conocimiento de las ciencias sociales y no pertenecían al plano ideológico. Por otra parte, en la visión de este grupo, la tarea educativa tenía preeminencia sobre la instrucción:

Hay que educarle el carácter, hay que hacer del niño una voluntad poderosa que

40. Ibídem.

41. Ibídem.

42. Íbidem. 
unido al conjunto de conocimientos que se le haya enseñado hará de él un hombre fuerte, moral e intelectualmente y eso sólo se consigue con la educación anarquista ya que el maestro no tendrá un criterio social $\mathrm{y}$ otro individual, como le pasa al director de la Escuela Integral. ${ }^{43}$

La objeción a las posturas de Albano Rosell consistía fundamentalmente en haber abdicado de los principios anarquistas al propiciar una institución que ponía en un mismo nivel al anarquismo y a las demás tendencias ideológicas, violentando de este modo sus principios sociológicos y científicos. La crítica alcanzó también la integridad personal de Rosell ya que, se lo acusó de tener un criterio privado como anarquista y un criterio "social" al defender una educación racionalista "anti-anarquista". Profesar ideas ácratas debía conducir, en esta interpretación, a defender una educación anarquista, si no se quería correr el riesgo de hipocresía o doble conciencia.

Esto no implicaba, sin embargo, a su juicio, que tal declaración de principios conllevara una imposición:

No queremos que los niños sean anarquistas... lo que creemos es que debe dársele a la niñez una educación antiautoritaria como antirreligiosa, pues no concebimos que la enseñanza neutral sea racionalista; tocante a las escuelas del Estado creemos que están en el mismo lugar que las religiosas como las neutrales ya sean particulares o patrocinadas por cualquier Liga. ${ }^{44}$

43. Ibídem.

44. “¿Racionalismo o anarquismo? Para El Anarquista”, nota al pie de los editores, en El Anarquista, Montevideo, 28/6/1913, № 6, p. 1.
Rosell estaba de acuerdo con el carácter antiautoritario de la educación, pero precisamente por esto, discrepaba en la intención de "infundir" a la niñez "ideas preconcebidas, de las que no se sienten todavía necesidad, abusando de la autoridad que las personas mayores tenemos sobre los pequeños". ${ }^{45}$ Es posible pensar que la experiencia de la Escuela Integral tuvo, en los hechos, un carácter anti-autoritario y en ese sentido, los "doctrinarios puros" 46 debieron valorar el hecho de que grupos más amplios apoyaran un emprendimiento que cuestionaba directamente la educación pública estatal. La exigencia que dicha escuela educara a los niños explícitamente en los postulados anarquistas parecía una pretensión demasiado torpe, dado el momento. Indudablemente otros aspectos que involucraron elementos subjetivos, condicionaron el apoyo.

En el número siguiente apareció como interlocutor Antonio Marzovillo, conocido activista, miembro del núcleo que editaba

45. D’ORE, Laureano, "Los silogistas de las ideas. Comentarios sobre Educación racionalista”, en Infancia, Montevideo, 7/1913, No 19, p. 73.

46. Existió una tendencia a la interna del movimiento anarquista montevideano y rioplatense que buscó defender ciertos principios básicos del anarquismo, por los que fueron denominados "doctrinarios" o "puristas". Con estas palabras se expresaba un anarquista, "amigo" de José Borobio en una carta personal, pero publicada en El Anarquista como modelo de aquellos que, confundidos en sus ideas, prestaban colaboración a las luchas electoralistas del partido colorado; la intención del escritor, pretendía hacerlo cambiar de opinión: "Persistir en la propaganda de principios puros y envolverse en un doctrinarismo tan inactual como el tuyo, es tan estéril como fuera de sentido. Al final de cuentas ¿qué podrás conseguir? Una decepción más y que todo continúe sino peor -pues tu conducta facilita a los reaccionarios- lo mismo que antes, lo mismo que siempre”. En “¿Polémica? Carta de un ex-revolucionario", en El Anarquista, Montevideo, 16/5/1913, № 3, p. 4. 
El Anarquista. ${ }^{47} \mathrm{La}$ inclusión de este artículo demostraba que la discusión no había quedado laudada a pesar de la intención de Rosell de no "remover más la charca". Si bien se reconocía a Marzovillo como una "garantía de seriedad y nobleza”, la redacción especificó que este artículo, "es la prueba más elocuente de la pasión y sectarismo que domina a ciertos llamados anarquistas" en Montevideo. ${ }^{48}$

En la visión de Marzovillo, desde la muerte de Ferrer i Guardia los racionalistas habían insistido en una educación para la niñez en la que no interviniera "la sugestión de la idea personal del profesor", de modo que, de cada alumno "surja un ser que por sí mismo, por deducción propia, se determine por tal o cual cosa de pensar, y que, en conclusión, la tal enseñanza no debe, no puede ser anarquista". Esta postura, para Marzovillo, desconocía en el fondo lo que implicaba el ideal ácrata, entendido como el de libertad para cada individuo. En su opinión, tenía por objetivo "hacer de cada humano un ser independiente, capaz de guiarse a sí mismo, sin imposición de ninguna especie, sin autoridad exterior sino respondiendo cada cual a su único raciocinio". ${ }^{49}$

47. Militante anarquista de origen italiano (1880- 1959). Escapando a las autoridades italianas como consecuencia de la Revolución de Milán en 1900, recala en Buenos Aires, donde ejerció el oficio de peluquero. De intensa actividad propagandística -fue colaborador en la revista L'Avenire y La Protesta Humana, entre otras- se traslada a Montevideo en febrero de 1905 expulsado por la aplicación de la Ley de Residencia. En esa ciudad, participa en las actividades del Centro Internacional de Estudios Sociales. Fue admirador de la propuesta pedagógica de Francisco Ferrer.

48. Nota de Redacción, en MARZOVILLO, Antonio, “¿Racionalismo o anarquismo?”, en Infancia, Montevideo, No 20, 8-9/1913, p. 104.

49. Ídem, p. 103.
Es posible constatar en la tradición libertaria la concepción de que "el anarquismo no impone nada, sino que enseña a cada cual a saberse desenvolver" ${ }^{50}$ De esto se deduce que no hay antagonismo entre la enseñanza racionalista y la finalidad anarquista, más bien, según Marzovillo, por el contrario, todo parece indicar que los postulados de unos y otros son "idénticos": no existe la autoridad infalible, por lo tanto, es necesario consultar todas las opiniones posibles y siempre salvaguardando la decisión personal. Cada individuo debe pensar y obrar bajo su responsabilidad, hacer que se respete su autonomía y respetar la de los otros. Como corolario entonces, tenemos que el anarquismo es "sinónimo de libertad y no de imposición" 51

nosotros no queremos sugestionar, imponer ideas a ninguno, sino llamar la atención a todo el mundo para que, cada cual, por deducción propia acepte lo que cree mejor y crea y viva como mejor le plazca, sin que por esto sea obstáculo para el libre desenvolvimiento de los demás. ${ }^{52}$

50. Ibídem.

51. La actitud de Marzovillo se inspiró -según él mismo refiere- en la de Pietro Gori, especialmente en el texto “Ciencia y Religión”, editado en Montevideo en 1911 en ocasión de su fallecimiento. En él, Gori argumentó que entre la religión y la ciencia, los anarquistas optaran siempre por ésta última, no solamente por una convicción teórica, sino también por amor a la humanidad y a nosotros mismos. No obstante, esto no significa que los anarquistas quieran imponer el dogma del ateísmo al resto de las personas, las convicciones no se imponen, se propagan con "la única fuerza de la lógica y el razonamiento”. Tomado de MARZOVILLO, Antonio, "Racionalismo...”, Op. Cit., p. 103. El texto original puede consultarse en GORI, Pietro, "Ensayos y conferencias", Disponible en: <https://es.slideshare.net/ guest8dcd3f/ensayos-y-conferencias-pietro-gori>.

52. Ibídem. 
No había diferencia entre la forma que querían los racionalistas que los niños se educasen y la que proponían los anarquistas. La discrepancia radicaba más bien en el alcance: "la ventaja enorme" estaba del lado anarquista, sostuvo Marzovillo, ya que, "mientras ellos dedican su tiempo a los niños, nosotros abarcamos a todos; hombres, mujeres y niños". ${ }^{3}$

Esta distinción, señalada por Marzovillo, mostraba la plena conciencia que se tenía por parte de grupos anarquistas de otro sector que se iba configurando lentamente y que tenía en Albano Rosell a uno de sus representantes más destacados. Basando sus orígenes en concepciones libertarias, este grupo fue priorizando la educación de la niñez al punto de convertirla en el énfasis casi exclusivo de su accionar, unido a un celoso cuidado de una educación antidogmática, no exenta de contradicciones por cierto.

Los redactores de Infancia cuestionaron este pretendido achicamiento de miras. En su concepción, Marzovillo había caído en un malentendido "bastante común": creer que la educación racionalista era asunto de colegios, de aula, de textos, y no reconocía "la amplitud de horizontes que ofrece el cuidado de la infancia y la influencia social de la escuela de educación integral". Sostenían que todo centro racionalista debía actuar en conjunto con el hogar del niño, con los padres, actividades fuera del horario escolar, todo lo que involucrase una continuidad entre la educación de la niñez y los adultos. ${ }^{54}$ Aunque

\section{Ibídem.}

54. La Redacción, notas a MARZOVILLO, Antonio, "Racionalismo o anarquismo", en Infancia, Montevideo, 10/1913, No 21, p. 104. es de recibo esta objeción sobre el alcance de la educación racionalista en la sociedad, no había en esta intervención, nada que refutara la idea de identidad de propósitos entre una y otra visión, como sostenía Marzovillo.

Como puede verse, la discusión teórica que se había reclamado, al fin se estaba dando. Sin embargo, los temas vinculados a la ética de algunos militantes anarquistas seguían estando presentes. Marzovillo subrayaba un punto de acuerdo: "los hombres que quieren formar una sociedad mejor y que no empiezan por mejorarse a sí mismos, no pueden hacer nada bueno, al contrario, son obstáculo de la realización de sus mismos deseos". ${ }^{55}$

En el mes siguiente, otro interlocutor de seudónimo "Alew" retomaría la discusión. En su opinión, no había identidad entre racionalismo y anarquismo: existía entre ellos importantes diferencias de propósito y de medios. A su juicio, la estrategia de Marzovillo de enumerar citas de autores anarquistas poco o nada probaba al respecto,

me parece que tuviera el propósito no tanto de hacer teoría, sino preferentemente dirimir pequeñas cuestiones, tal vez ajenas a la materia aquí tratada, que suelen suscitarse entre los partidarios de dichas escuelas, señalando a ambos bandos para zanjar posibles conflictos, sendos campos de actividad. ${ }^{56}$

La objeción de Alew no daba cuenta de porqué apelar a la tradición era un recurso ilegítimo, especialmente cuando lo que Marzovillo quería mostrar eran citas que reflejaran una

55. Ibídem.

56. ALEW, "Comentando un artículo", en Infancia, Montevideo, 11/1913, No 22-23, p. XLI. 
trayectoria de acción. En continuidad con esto, la ilegitimidad de la tradición de un bando podría trasladarse fácilmente al otro, $y$ así no tener en cuenta la enorme acumulación de propaganda racionalista que la revista venía haciendo a través de diversos autores. Por otra parte, no parecía colaborar con la discusión el hecho de atribuir intencionalidades en la exposición del oponente, si Marzovillo deseaba hacer teoría o limar asperezas a la interna del movimiento anarquista, poco importaba a la hora de discutir las relaciones entre racionalismo y anarquismo. Alew no asumió el argumento de Marzovillo y no lo discutió por sí mismo.

Otro aspecto que llama la atención en la opinión de Alew es la oposición que estableció entre anarquismo y racionalismo, plagada de estereotipos, simplificadora y reductiva. Para Alew, el anarquismo era una doctrina "pasada de moda”, en el plano económico y político ofrecía "soluciones irrealizables", estimulando además, las "dimensiones más oscuras" -entiéndase, "pasionales"- del ser humano. ${ }^{57}$ En oposición, la educación racionalista "eleva" la cultura popular, combate todo dogmatismo y prepara, en definitiva a los individuos, de mejor manera para "ensayar con éxito nuevas formas sociales de avanzada civilización". ${ }^{58}$

57. Nótese por ejemplo los supuestos que encierra esta pregunta compleja: “¿Puede confundirse la labor del maestro que cultiva del niño toda feliz disposición a la vida, trayendo a la acción creadora tesoros de aptitudes, salvadas de esta suerte del olvido y desestimación de la ignorancia ambiente, mediante el empleo de métodos científicos y razonados, con la pretensión pasada de moda de regular el vasto océano de la vida social por fórmulas doctrinarias de discutible realización práctica que hacen abstracción completa de tantas y tantas pasiones que afean el alma humana"? ALEW, "Comentando un artículo...”, Op. Cit., p. XLI.

58. Ibídem.
Esta forma de polemizar, fabricando un rival estereotipado y por tanto, fácilmente refutable, no buscó evidentemente producir acuerdos, más bien socavó los puentes que con dificultad Marzovillo estaba tratando de erigir.

Otro argumento que Alew presentaba, si se quiere, más interesante, apuntaba a mostrar que Marzovillo realizaba una conclusión "infundada", porque partía de una definición demasiado amplia, "se aplica a darnos una definición de racionalismo y anarquismo, tendiente a dejar sentado que proponiéndose el primero libertar al niño de la tiranía escolar de los antiguos métodos, bien podía considerarse una escuela del segundo, que propendía al mismo resultado respecto al hombre". En este sentido, en el "terreno común de los conceptos vagos", hasta las opiniones más opuestas concuerdan en algún punto, lo importante "será decir cómo lo harán, a fin de poder valorar su eficacia". Pide a los anarquistas que haga entender su "contenido real", su "sustancialidad propia". 59

A esta diversidad de propósitos correspondían, a su vez, medios distintos que venían a constituir nuevas diferencias características, afirmaba Alew. Los procedimientos del movimiento anarquista eran "por necesidad" revolucionarios, plagados de "elementos pasionales" y alejados, por tanto de los métodos aplicados por la enseñanza racional.

Las ideas anarquistas servían de "pomposo penacho amuchas vehemenciasy nerviosismos, agitaciones y acritudes, exasperaciones y desconfianzas". Como consecuencia de esto, la diferencia se manifestaba también en los

59. Ibídem. 
“agentes" que llevaban adelante una y otra empresa:

Así concebimos al maestro, bondadoso, independiente... como conviene al obrero de espíritu que tiene a su cargo la delicada misión de preparar los hombres del futuro, apartando de ellos prejuicios $\mathrm{y}$ pasiones enceguecedoras y velando, porque la civilización que apenas alborea los encuentre bien prevenidos y dispuestos a ofrecer el concurso de voluntad e inteligencia que ella reclamará de todos los buenos. ${ }^{60}$

Se sobreentiende que un educador anarquista adoptaría las cualidades opuestas por el solo hecho de defender esas ideas.

En la visión de Marzovillo el anarquismo de ningún modo era un dogma: "ante todo y sobre todo es una aspiración", un deseo que no busca imponerse a los demás; "así como en el orden económico no acepta un sistema único determinado... en la moral, no tiene tampoco imposición o legislación colectiva sobre el individuo; (cada cual obrará según sus gustos, educación o inclinaciones), respetando siempre la libertad ajena" ${ }^{61}$ Prueba de ello era que entre los mismos teóricos del anarquismo había discrepancias en la forma de interpretarlo. Era preciso reconocer que, tanto el anarquismo como el racionalismo estaban sujetos a la evolución del pensamiento, $\mathrm{y}$ "de ninguna de ellas podremos decir que dicen su última palabra". ${ }^{62}$

60. Ibídem.

61. MARZOVILLO, Antonio, "Definiendo", en Infancia, Montevideo, 5-6/1914, № 29, p. 38.

62. MARZOVILLO, Antonio, "Racionalismo y Anarquismo", en Infancia, Montevideo, 1/1914, № 25 , pp. 8-9.
Una indicio más, que a los ojos de Marzovillo, demostraba que el anarquismo tenía identidad con el sistema racional de enseñanza, era que la mayoría, por no decir todos los que luchaban en el mundo por este sistema y que daban su libertad y hasta su vida, eran "precisamente anarquistas". Lo mismo pasaba con gran parte de los maestros y profesores racionalistas, "si dedican su tiempo a esta clase de enseñanza, es porque saben o creen que educando a los niños en una forma así libre, tendrán como resultado planteles de futuros hombres libres, es decir, de anarquistas, porque: anarquía y libertad son sinónimas". ${ }^{63}$

Marzovillo no retomó la importante objeción de Alew que señalaba las deficiencias en la práctica de los emprendimientos educativos de inspiración libertaria. Parecería sensato entender que una educación sería liberadora si lo demostraba en su práctica cotidiana y durante un tiempo prudente que permitiera una evaluación certera. Vale consignar, a su vez, que las experiencias que sirvieron de inspiración al movimiento libertario no pudieron sostenerse en el tiempo, fundamentalmente, por condicionamientos externos. ${ }^{64}$ Ahora bien, el reclamo de Alew parecía estar señalando la falta de cohesión del anarquismo local para llevar adelante efectivamente una escuela racionalista. Cuesta comprender, a los ojos de una mentalidad

63. Ibídem.

64. Ninguna de las experiencias anteriores pudo alcanzar este rango: la escuela de León Tolstoi, cerrada por la persecución policial y las presiones de la Iglesia Ortodoxa; la experiencia educativa de Paul Robin también fue cerrada por el gobierno; La Ruche dirigida por Faure fue cerrada por los enormes problemas económicos acaecidos en el contexto de la Gran Guerra; La Escuela Moderna de Barcelona, cerrada por el gobierno español después de los sucesos de Barcelona. 
estructurada con una lógica jerárquica, de "partido", que las diferentes posturas de los activistas con respecto a la implantación de escuelas racionalistas, no era sino el resultado natural del modo de vivir "su" anarquismo. En este sentido, las exigencias de Rosell de alinear tras la "Escuela integral" de Montevideo a todo el movimiento obrero, y con ellos, a los anarquistas, pudo interpretarse como una expresión voluntarista de homogeneidad y uniformidad en un sector que necesitaba respetar las diferencias y los disensos.

En el número de enero de 191, Otto Niemann asumió la dirección de la Liga y de Infancia, participando inmediatamente en la discusión. Sin embargo ya no lo guiaba la preocupación por "deslindar términos", sino que perseguía un fin integrador. Se proponía ampliar la estrechez con la que Alew había entendido el racionalismo y asumir una actitud de "barrer hacia dentro", en el sentido de limar las aristas de las convicciones más duras y tender a hacer pesar más los puntos de acuerdo. ${ }^{65}$

Para Niemann todo el mundo podía ser racionalista, sin distinción de ideas. Aún más, "cuando el racionalismo es aplicado a la educación para el completo desarrollo de la infancia... pueden ser racionalistas todos aquellos que tienen ideas que son el fruto de una investigación y estudio consciente: los que no temen la discusión ni la crítica" ${ }^{66}$

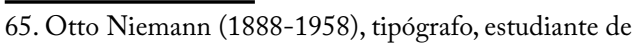
magisterio, fue fundador y director de la revista Educación Sociológica, (1911-1912) fue también director de Infancia desde el número 29 al 36 (mayo de 1914 a marzo de 1915).

66. TAMOINE, Octavio, "Los anarquistas y el racionalismo", en Infancia, Montevideo, 5-6/1914, No 29, p. 33.
Entre ellos, los anarquistas eran "los más implacables críticos de la sociedad presente" y esta actitud los llevaba a discutir constantemente los medios para llegar a su ideal. Niemann enfatizaba que "son los que, siempre, continuamente, quieren estar acompañados de lo más nuevo, lo más exacto, sin oponerse al perfeccionamiento humano hasta en lo insignificante". Esta actitud era quizás su "mayor obstáculo" a la hora de realizar un emprendimiento colectivo, "consiste en no detenerse y llamar a los que quedan: ¡eso es poco, más adelante!”. ${ }^{67}$

Es por esta "amplitud de miras", por este "desinterés" de ambición política que entre ellos se encuentra "la mayor parte de los elementos capaces de dar vida a la obra racionalista; son tal vez los únicos que no temen poner en manos de la infancia todo lo bueno, los únicos que desean el triunfo de la verdad y la justicia por encima de todos los ismos programados". ${ }^{68} \mathrm{La}$ exhortación final era una clara muestra de esta nueva actitud:
Todos los amantes a una humanidad nueva, deben cooperar, sin distinción de ideas sociales, a la preparación racional de la infancia para la formación del hombre- gobierno del hombre- voluntad. Y los anarquistas deben continuar siendo activos en la propaganda y acción racionalista. Nunca serán suficientes los esfuerzos que se realicen por esa obra de tanta trascendencia". ${ }^{69}$

Entre un anarquismo doctrinario que se desentendía de toda educación que no fuera ácrata y un racionalismo puritano,

67. Ibídem.

68. Ibídem.

69. Ibídem. 
siempre dispuesto a dejar fuera toda idea que tuviese un tufillo ideológico y pasional, podemos ver en la postura de Niemann una distancia prudente en la que es posible acercar las partes en vista de realizar una tarea concreta, sin lastimarse con las púas ajenas. Otto Niemann se mantuvo en esa posición intermedia, aunque con escaso éxito. En agosto de 1916 aparecía el último número de la revista Infancia, y con él, una de las últimas acciones de la LRM, que fue paulatinamente diluyéndose hasta su extinción total. Poco antes, Niemann había dejado planteada la pregunta si la acción de la LRM no debía volcarse a transformar estructuras al interior del Estado. Su opción de trabajar como director en una escuela experimental en el interior del país fue signo de este cambio que no tuvo seguimiento por parte de los grupos racionalistas o anarquistas. La exploración de su experiencia resulta aun una tarea pendiente para los investigadores.

¿Cuál hubiera sido la suerte del proyecto de la LRM si hubiese primado la actitud conciliadora de Niemann, más dispuesta a unificar esfuerzos que a dejar en claro las diferencias? Queda la sensación que desde su comienzo público, es decir, desde el primer número de su "órgano oficial", el proyecto estuvo fuertemente condicionado por una impronta puritana, moralizadora y de cierto mesianismo orgulloso. En ese sentido se planteaba una tarea "regeneradora de la humana especie", en la que aquellos que no estaban dispuestos a aceptar los lineamientos establecidos por los representantes más notables de la Liga, eran ubicados rápidamente en el bando opositor. Asimismo, en los grupos anarquistas que no apoyaron el emprendimiento, hubo incapacidad para acompañary fortalecer este espacio alternativo, exigiéndoles determinadas credenciales antes de que tuviera identidad propia. Lo que queda demostrado, no obstante, es que la discusión "anarquismo-racionalismo" muestra el posicionamiento que paulatinamente iban a ir adoptando dos sectores, con profundas raíces en las concepciones libertarias pero que, a partir de las discusiones sobre educación, irían tomando irremediablemente derroteros diferentes.

\section{Consideraciones finales}

E1 movimiento obrero montevideano contribuyó con una importante gama de emprendimientos y actividades a la alfabetización de los trabajadores. Esta tarea aparentemente coincidió con una preocupación más bien lábil por reflexionar sobre sus logros y dificultades, los supuestos que encerraba y el modo en que se engarzaba con su práctica revolucionaria. La Liga Popular para la Educación Racional de la Infancia constituyó una excepción. Agitando las aguas del acratismo, puso sobre la mesa todo un espectro de propaganda, descripciones y teorías pedagógicas, todo un lenguaje en favor de la causa racionalista. Las discusiones que tuvieron lugar en este periodo y que se desarrollaron preponderantemente en el escenario montado por la revista Infancia, mostraron que, en este lugar del mundo, el racionalismo no fue meramente una estrategia de los grupos anarquistas. $\mathrm{Si}$ bien se nutrió de éste último, las vicisitudes vernáculas determinaron prontamente su espacio autónomo. Varios indicios prueban esto, aunque todo haya comenzado por cierta retórica del énfasis. En primer lugar, el acérrimo antidogmatismo, que lo llevó 
especialmente a combatir cualquier intento de servir a la propagación del anarquismo, en tanto "idea hecha". Por otra parte, tal como se ve reflejado en este artículo, la decisión de influir dentro de la estructura estatal, consolidó la tendencia que reconocía al Estado como un interlocutor válido en los asuntos de la educación. La desconfianza a todo lo que fuera colaboración con el Estado, en el contexto de activistas que prestaron sus servicios al gobierno de Batlle y Ordóñez, agravó la distancia entre "anarquistas" y "racionalistas".

El estudio del lenguaje utilizado por los autores de la LRM, contribuye a complejizar ciertas opiniones usuales de la historiografía corriente. Por ejemplo, aquellas que señalan que la "educación racionalista" fue "un tipo específico de educación libertaria"; ${ }^{70}$ o parte de la estrategia del movimiento anarquista. También cuestiona la afirmación de que los planteamientos ideológicos en el Uruguay de este periodo, en términos generales, "reprodujeron", sin más, "la evolución del pensamiento social europeo". ${ }^{71}$ Es decir, nos ayuda a comprender la experiencia de la LRM en su especificidad, las complejidades de adaptación de las ideas racionalistas en Montevideo a inicios del siglo XX y, la trama de opiniones que sobre educación tuvo el movimiento anarquista en este periodo y el discurso educativo-pedagógico que produjo.

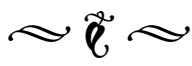

70. HERRERA, Diego, Las escuelas libertarias..., Op. Cit..

71. D’ELIA, Germán; MIRALDI, Armando, Historia del movimiento obrero en el Uruguay. Desde sus origenes hasta 1930, Ediciones de la Banda Oriental, Montevideo, 1984, p. 84. 


\section{Bibliografía}

ARAÚJO, Orestes, Historia de la Escuela Uruguaya, El siglo ilustrado, Montevideo, 1911.

ARDAO, Arturo, Racionalismo y liberalismo en el Uruguay, Universidad de la República, Montevideo, 1962.

BARRÁN, José, NAHUM, Benjamin, Historia Rural del Uruguay Moderno (1851-1885), Montevideo, 1967.

BARRÁN, José, Historia de la sensibilidad en el Uruguay. La cultura "bárbara", 1800-1860. El disciplinamiento 1860-1920, Banda Oriental, Montevideo, 2009.

BRALICH, Jorge, "Vaz Ferreira, el pedagogo que nunca fue a la escuela", en Revista Fermentario, Montevideo, 2009, No 3, disponible en: <http://www.fermentario.fhuce.edu.uy/index.php/fermentario/ article/view/55>.

CASTRO, Julio, El banco fijo y la mesa colectiva: Vieja y Nueva Educación, MEC, Montevideo, 2007.

D’ ELIA, Germán, MIRALDI, Armando, Historia del movimiento obrero en el Uruguay. Desde sus orígenes hasta 1930, Ediciones de la Banda Oriental, Montevideo, 1984.

FERNÁNDEZ, Gustavo, VIDAL, Daniel, Orígenes del $1^{\circ}$ de mayo y la Primera Huelga general en el Uruguay, Aportes, Montevideo, 2012.

GORI, Pietro, Ensayos y conferencias, Disponible en: <https://es.slideshare.net/guest8dcd3f/ensayos-yconferencias-pietro-gori>.

GROMPONE, Antonio, Ideología de Batlle, Arca, Montevideo, 2012.

HERRERA, Diego, Las escuelas libertarias en el contexto de estructuración y consolidación del sistema educativo argentino (1898-1915), Tesis de Licenciatura, Universidad de Buenos Aires, 2009. Disponible en: <http://comunicacion.fsoc.uba.ar/tesinas_publicadas/2141.pdf>.

HIERRO, Luis Antonio, Batlle. Democracia y reforma del Estado, Ediciones de la Banda Oriental, Montevideo, 1977.

IÑIGUEZ, Miguel, Esbozo de una Enciclopedia bistórica del anarquismo español, Fundación Anselmo Lorenzo, Madrid, 2001.

ISLAS, Ariadna, La Liga Patriótica de Enseñanza. Una historia sobre ciudadania, orden social y educación en el Uruguay (1888-1898), ediciones de la Banda Oriental, Montevideo, 2009.

LOUIS, Julio, Batlle y Ordoñez. Apogeo y muerte de la democracia burguesa, Nativa, Montevideo, 1969.

MUÑOZ, Pascual, La primera huelga general en el Uruguay. 23 de Mayo 1911, La Turba Ediciones, Montevideo, 2011.

MUÑOZ, Pascual, “1º de Mayo de 1913. La Tormenta Obrera”, en Tierra y Tempestad, Montevideo, 2013, 
No 16, pp. 8-9. Disponible en: <https://drive.google.com/file/d/0B3jwypu7Jr7PdnNWQmpwQ2hOR DVFV25wQnZ0Y0d5V2ZKRThv/edit>.

MUÑOZ, Pascual, Cultura obrera en el interior del Uruguay (Salto, Paysandú y Rocha 1918-1925), Lupita, Montevideo, 2015.

PORRINI, Rodolfo, "Izquierda uruguaya y culturas obreras. Propuestas al aire libre: pic-nics y paseos campestres en Montevideo, 1920-1950” en Revista Mundos do Trabalho, Campinas, 2011, V. 3, No 6, pp. 105-129. Disponible en: <http://dx.doi.org/10.5007/1984-9222.2011v3n6p105>.

RAMA, Carlos, José Pedro Varela, sociólogo, Editorial Medina, Montevideo, 1957.

SOLÀ I GUSSINYER, Pére, "Los grupos del magisterio racionalista en Argentina y Uruguay hacia 1910 y sus actitudes ante la enseñanza laica oficial” en Historia de la Educación, Salamanca, 1982, V. 1, pp. 55143. Disponible en: <http://revistas.usal.es/index.php/0212-0267/article/view/6457>.

SURIANO, Juan, Anarquistas. Cultura y politica libertaria en Buenos Aires 1890-1910, Manantial, Buenos Aires, 2008.

TOLSTOI, León, Obras Completas, T. II, Aguilar, Madrid, 1981.

VANGER, Milton, José Batlle y Ordóñez. Pensador, politico, historiador, antropólogo. 1902-1907, Eudeba, Buenos Aires, 1968.

VARELA, José Pedro, La Educación del Pueblo, Sociedad de Amigos de la Educación Popular, Montevideo, 2005.

VARELA, José Pedro, De la Legislación escolar. Consideraciones teórico-prácticas sobre la organización de la instrucción pública precedidas de un estudio sobre nuestro Estado actual y sus causas y seguida de un Proyecto de Ley de Educación Común para la República Oriental del Uruguay, Zonalibro, Montevideo, 2006.

VAZ FERREIRA, Carlos, Sobre los problemas sociales, Homenaje de la Cámara de Representantes de la República Oriental del Uruguay, Montevideo, 1963.

ZUBILLAGA, Carlos, BALBIS, Jorge. Historia del movimiento sindical uruguayo T. I, Cronología y fuentes (hasta 1905), Ediciones de la Banda Oriental, Montevideo, 1985.

ZUBILLAGA, Carlos, "Luchas populares y cultura alternativa en Uruguay: el Centro Internacional de Estudios Sociales” en Siglo XIX, Montevideo, 1988, V. VI, pp. 11-39.

ZUBILLAGA, Carlos, "El difícil camino de la participación política, población, ciudadanía y electorado (1898-1918)", en Fernando Devoto y Marcela Ferrari (compiladores) La construcción de las democracias rioplatenses: proyectos institucionales y prácticas políticas, 1900-1930, Editorial Biblios, Montevideo, 1994.

ZUBILlAGA, Carlos, Perfiles en sombra. Aportes a un diccionario biográfico de los orígenes del movimiento sindical en Uruguay (1870-1910), Librería de la Facultad de Humanidades y Ciencias de la Educación, Montevideo, 2008. 
ZUM FELDE, Alberto, Proceso intelectual del Uruguay y crítica de su literatura, T. III, Imprenta Nacional Colorada, Montevideo, 1930.

ZUM FELDE, Alberto, Proceso histórico del Uruguay, Arca, Montevideo, 1972. 